\title{
GSTP1 promoter hypermethylation is an early event in breast carcinogenesis
}

\author{
Ji Shin Lee
}

Published online: 11 July 2007

(C) Springer-Verlag 2007

Unfortunately the following acknowledgement was not published in the body of the paper.

Acknowledgements This work was done in the laboratory of Dr. Sukumar at the Johns Hopkins Oncology Center, Baltimore, MD. I thank Saraswati Sukumar and Mary Jo Fackler for providing guidance and support. This work was supported by the NIH-SPORE grant P50 CA88843 to SS.

The online version of the original article can be found at http://dx.doi. org/10.1007/s00428-007-0421-8.

J. S. Lee $(\bowtie)$

Department of Pathology, Chonnam National University Medical

School and Research Institute of Medical Sciences,

Gwangju 501-746, South Korea

e-mail: jshinlee@hanmail.net

\section{J. S. Lee}

Department of Pathology,

Chonnam National University Hwasun Hospital,

160, IIsim-ri, Hwasun-eup, Hwasun-gun,

Jeollanam-do 519-809, South Korea 